\section{Defecto óseo de Stafne: hallazgo en radiografía panorámica}

\section{Stafne bone defect: findings on panoramic radiography}

\section{Sr. Editor.}

La cavidad ósea de Stafne es un defecto óseo de forma redondeada u ovalada, puede presentarse de manera unilateral o bilateral teniendo un diámetro promedio de entre 1 a $3 \mathrm{~cm}$. Mayormente se encuentra ubicada en la zona posterior lingual de la mandíbula por debajo del conducto del nervio dentario inferior, pero también se puede localizar en otras zonas de la mandíbula. Esta entidad, al no generar sintomatología, generalmente es un hallazgo en la radiografía panorámica odontológica; pudiendo describirse como una imagen radiolúcida unilocular de forma redondeada, de límites definidos y bordes corticalizados (Figura) ${ }^{1-6}$.

Se evidencia con mayor frecuencia en pacientes adultos varones, localizándose en el hueso esponjoso y en algunos casos al examen clínico llegan a palparse por falta de superficie ósea. Puede presentar distintas variaciones siendo uni o bilaterales, multiloculares, con límites bien o mal definidos, y en ocasiones hasta pueden ser sintomáticos. Esto nos puede llevar a duda, es por ello que en algunas circunstancias se sugiere el uso de técnicas imagenológicas adicionales para su correcto diagnóstico tales como la tomografía computarizada de haz cónico, tomografía computarizada multicorte y la resonancia magnética ${ }^{2,3,6}$.

La etiología aún se desconoce, sin embargo, se han propuesto muchas teorías acerca del desarrollo de esta entidad las cuales son: atrofia del hueso mandibular inducido por presión de la glándula submandibular, hipertrofia de la glándula submandibular, erosión debido a una compresión vascular o la calcificación incompleta del cartílago de Meckel durante su osificación; por lo cual ha recibido varias denominaciones como: cavidad ósea estática, cavidad idiopática, depresión mandibular de la cortical lingual. Otros autores también lo denominan como pseudoquistes por no tener un revestimiento epitelial ${ }^{2,4,5}$.

Es importante la identificación y diagnóstico de esta entidad. Actualmente el uso de la tomografía computarizada de haz cónico o la resonancia magnética son técnicas no invasivas que ayudan a obtener el diagnóstico final de este hallazgo, por lo cual no es necesario un análisis anatomopatológico ${ }^{1-6}$. No se requiere de algún tipo de tratamiento quirúrgico por ser una variante anatómica ${ }^{1,3-6}$; pero es recomendable hacer un seguimiento radiográfico anual ya que en casos muy raros puede haber algún tipo de transformación maligna de las glándulas salivales ${ }^{1,3}$.

\section{Carta al Editor}

Fernando Russbelts Sthorayca Retamozo 1,a, Carlos Darío Merino Bustamante ${ }^{1, a}$, Vilma Elizabeth Ruiz García de Chacón 1,a,b

${ }^{1}$ Universidad Peruana Cayetano Heredia, Facultad de Estomatología, Lima, Perú.

a Cirujano Dentista.

${ }^{\mathrm{b}}$ Especialista de Radiología Oral y Máxilofacial.

\section{Correspondencia:}

Fernando Russbelts Sthorayca Retamozo Correo electrónico: fernando.sthorayca@upch.pe Calle Bolívar 434. Tacna-Perú.

\section{Coautores:}

Carlos Darío Merino Bustamante

carlos.merino.b@upch.pe

Vilma Elizabeth Ruiz García de Chacón

vilma.ruiz.g@upch.pe

Conflicto de intereses: ninguno

\section{Recibido: 25/11/19}

Aprobado: 17/12/19

Publicado: 09/05/20 


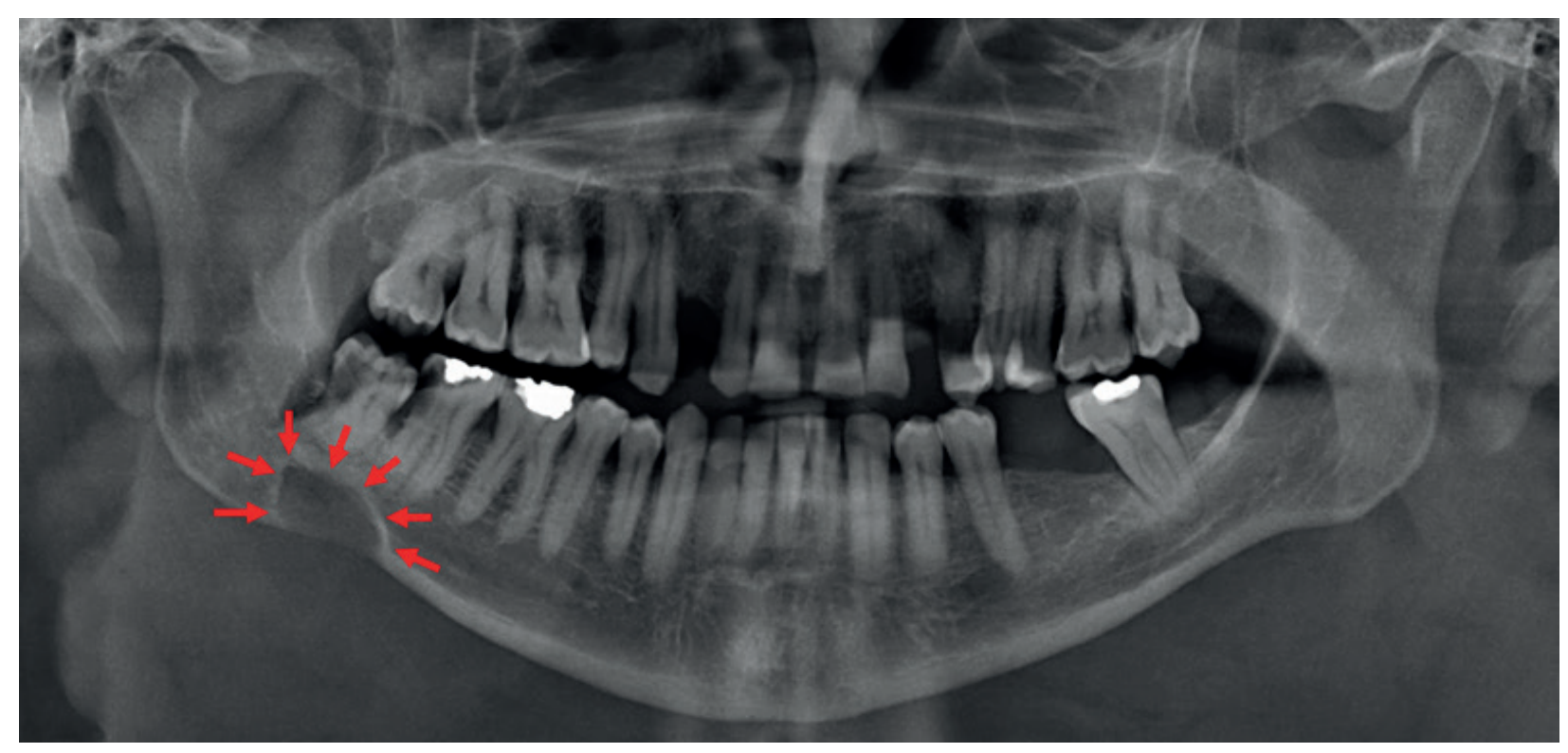

Figura. Radiografía panorámica donde se evidencia una imagen radiolúcida de forma ovalada de límites definidos y bordes parcialmente corticalizados proyectada sobre del conducto dentario inferior y con compromiso de la basal mandibular en la región antegonial del lado derecho, signos radiográficos compatibles con defecto óseo de Stafne. Imagen tomada del archivo del Servicio de Radiología Oral y Maxilofacial de la FE - UPCH

\section{Referencias bibliográficas}

1. Schneider T, Filo K, Locher MC, Gander T, Metzler P, Grätz KW, et al. Stafne bone cavities: systematic algorithm for diagnosis derived from retrospective data over a 5-year period. Br J Oral Maxillofac Surg. 2014;52(4):369-74.

2. Kaya M, Ugur KS, Dagli E, Kurtaran H, Gunduz M. Stafne bone cavity containing ectopic parotid gland. Braz J Otorhinolaryngol. 2018;84(5):669-72.

3. Hisatomi M, Munhoz L, Asaumi J, Arita E. Stafne bone defects radiographic features in panoramic radiographs: Assessment of 91 cases. Med Oral Patol Oral Cir Bucal. 2018;24(1):12-9.
4. Assaf AT, Solaty M, Zrnc TA, Fuhrmann AW, Scheuer H, Heiland M, et al. Prevalence of Stafne's Bone Cavity - Retrospective Analysis of 14,005 Panoramic Views. In Vivo. 2014;28(6):1159-64.

5. Taysi M, Ozden C, Cankaya B, Olgac V, Yıldırım S. Stafne bone defect in the anterior mandible. Dentomaxillofac Radiol. 2014;43(7):1-5.

6. Boffano P, Gallesio C, Daniele D, Roccia F. An unusual trilobate Stafne bone cavity. Surg Radiol Anat. 2013;35(4):351-3. 